\title{
A. Toomingas, S. E. Mathiassen, and E. W. Tornqvist (eds): Occupational Physiology
}

\author{
CRC Press, Boca Raton, Florida, 2012, 297 pp, \$89.95 (hardbound)
}

\author{
Bruce A. Barron
}

Published online: 4 October 2012

(c) Springer Science+Business Media New York 2012

The construct of studying worker physiology and their jobs is defined as occupational physiology. Through the integration of work physiology, muscle physiology, and climate physiology; practitioners of occupational physiology are able to assess worker capacity (both physical and mental) and corresponding workplace demands to maximize employee health, safety, and productivity. Coincidentally, the concept of total worker health has recently emerged as an initiative in the United States and elsewhere. Total worker health and occupational physiology share a common goal of injury and illness prevention to optimize employee health and wellness. Therefore, the publication of Occupational Physiology could not have been more timely.

Occupational Physiology is written by experts in the field. As a result, the book is clearly written, well-referenced, and logically sequenced from one chapter to the next. The first chapter provides a well-written summary of concepts critical to understanding the basics of occupational physiology, providing a firm foundation for the remainder of the book. Rather than using the traditional organ system approach to physiology, the editors organized the book in alignment with workplace demands. Therefore, Occupational Physiology is comprised of eight major chapters that assess the physiology of employees exposed to work involving high-energy expenditure, high muscle forces, awkward postures, repetitive movements, prolonged static postures, high mental loads, disrupted diurnal rhythms, and heat and cold. The chapters that address shift work and work associated with high levels of mental strain are particularly noteworthy because the exposures and physiologic responses are not easy to recognize, evaluate, and control. Furthermore, each chapter contains fact boxes and figures that further elucidate and enhance the text. Key references and suggestions for additional reading are also provided at the end of each chapter, making Occupational Physiology a valuable reference source.

Well-written and easy to read, Occupational Physiology is an evidence-based authoritative book that applies the discipline of physiology to the workplace setting. The authors address important physical and mental workplace demands and their impact on employee health, safety, and performance. More importantly, the authors proffer tactics and strategies to recognize, evaluate, and control common workplace hazards, thereby mitigating health and safety risks. Although Occupational Physiology does not fall into the "must read" category, this book should prove to be of interest and value to physiology, occupational health, safety, and ergonomic students and professionals, in addition to disability case managers and other professionals involved in employee wellness, loss prevention, and work organization. Despite its accolades, readers should realize that even though this book is touted for its novel approach to occupational physiology, its contents and organization are quite similar to ergonomic approaches to workplace health, safety, and performance.

B. A. Barron ( $\square)$

Division of Occupational and Environmental Medicine,

University of Rochester School of Medicine and Dentistry,

Rochester, NY, USA

e-mail: bruce_barron@urmc.rochester.edu 